\title{
Dr. Robert L. Bennett: pioneer and definer of modern physiatry.
}

John F. Ditunno, Jr

Thomas Jefferson University

Richard E. Verville

Powers Pyles Sutter \& Verville PC

Follow this and additional works at: https://jdc.jefferson.edu/rmfp

Part of the Rehabilitation and Therapy Commons

Let us know how access to this document benefits you

\section{Recommended Citation}

Ditunno, Jr, John F. and Verville, Richard E., "Dr. Robert L. Bennett: pioneer and definer of modern physiatry." (2013). Department of Rehabilitation Medicine Faculty Papers. Paper 50.

https://jdc.jefferson.edu/rmfp/50

This Article is brought to you for free and open access by the Jefferson Digital Commons. The Jefferson Digital Commons is a service of Thomas Jefferson University's Center for Teaching and Learning (CTL). The Commons is a showcase for Jefferson books and journals, peer-reviewed scholarly publications, unique historical collections from the University archives, and teaching tools. The Jefferson Digital Commons allows researchers and interested readers anywhere in the world to learn about and keep up to date with Jefferson scholarship. This article has been accepted for inclusion in Department of Rehabilitation Medicine Faculty Papers by an authorized administrator of the Jefferson Digital Commons. For more information, please contact: JeffersonDigitalCommons@jefferson.edu. 


\section{TITLE:}

Dr. Robert L. Bennett: Pioneer and Definer of Modern Physiatry.

\section{AUTHORS:}

John F. Ditunno, Jr., MD ${ }^{1}$ and Richard E. Verville, JD ${ }^{2}$

${ }^{1}$ Regional Spinal Cord Injury Center of the Delaware Valley, Department of Rehabilitation Medicine, Thomas Jefferson University, Philadelphia, Pennsylvania, USA

${ }^{2}$ Powers Pyles Sutter \& Verville PC, Washington, DC, USA

This material was not presented at an AAPM\&R Annual Assembly.

There are no funding sources for this paper nor the research involved in preparing it.

\section{CORRESPONDING AUTHOR}

John F Ditunno, Jr., M.D

Regional Spinal Cord Injury Center

Thomas Jefferson University

132 South $10^{\text {th }}$ Street, 375 Main

Philadelphia, PA 19107

Phone: 215-955-6579

Fax: 215-955-5152

Email: John.Ditunno@jefferson.edu 
*3.) Blinded Manuscript (without personal identifiers)

1 TITLE:

2 Dr. Robert L. Bennett: Pioneer and Definer of Modern Physiatry.

3

4

5

6

7

8

9

10

11

12

13

14

15

16

17

18

\{D0427971.DOC / 1$\}$

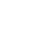

9

10

1

2

3

4

5

6

7

8

\{D0427971.DOC/1\}

Binded Manuscript (without personal identifiers)

(1)

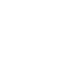

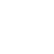

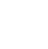

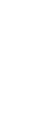

.

(n)

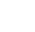

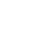


ABSTRACT:

20 Few physiatrists today would appreciate Dr. Robert L. Bennett's contributions to our specialty, 21 since he most commonly was associated with poliomyelitis, a cured disease for over a half

22 century. Less are aware of the pioneering fusion of physical medicine in 1941 by Krusen's first

23 resident with the independent living environment of the Georgia Warm Spring Foundation

24 (GWSF) created by a USA president. Bennett recognized polio/GWSF as the workshop and

25 laboratory for showcasing the new specialty of Physical Medicine and Rehabilitation (PMR). He

26 taught us that accurate muscle testing determined the plan of muscle reeducation, which led to

27 functional training with a rehabilitation team and this approach was equally valid for

28 complicated diseases such as spinal cord injury and traumatic brain injury. His leadership, as

29 chair of the American Board of PMR for 10 years, is unequaled in tenure and vision. In over 100

30 articles, he defined Physiatry to all physicians and allied health professionals and predicted the

31 physiatrist of tomorrow would need to be a complete physician who specialized in certain

32 diseases that he could care for, because of his unique set of knowledge and skill. He founded the

33 first department of Physical Medicine in the South at Emory University in 1945, trained over a

34 hundred fellows and residents and played a role in the establishment of the Research and

35 Training Center 20 years later. He taught and practiced as Professor of Rehabilitation Medicine

36 until his death in 1983 and is still remembered by several generations that were inspired by his

37 teaching. 
While most young physiatrists are aware of Frank Krusen and Howard Rusk as the

47 fathers of Physical Medicine and Rehabilitation (PM\&R) respectively, ${ }^{1}$ few would recognize the

48 name of Robert Bennett, who taught us what a physiatrist is. His leadership efforts are worthy of

49 our highest recognition, since he defined the field of Physical Medicine during its formative

50 years and embraced Rehabilitation in his daily practice and teaching at the Georgia Warm

51 Springs Foundation (GWSF). His pioneering effort of implementing the basic skill set of PM\&R

52 began immediately following his residency in 1941 before the above recognized "fathers" had

53 agreed on the link between Physical Medicine and Rehabilitation. ${ }^{2} \mathrm{He}$ is cited for his definition

54 of physiatric practice as it related to poliomyelitis, ${ }^{3,4}$ but his vision, scope and appreciation of our

55 specialty encompassed much more and is as relevant today as 70 years ago. This paper is meant

56 to impart some of the recognition he richly deserves.

$57 \quad$ Attracted to Physical Medicine by Frank Krusen, Bennett was his second resident ${ }^{5}$ and 58 the first to earn a Master of Science degree in 1940 from the Mayo Foundation and University of 59 Minnesota. His recruitment to GWSF was the result of a charge to the current Medical Director of GWSF, Dr. C. “Ed” Irwin in 1940 by Basil O’Connor (Manager/President GWSF 1928-1972)

61 to hire a physician of physical therapy ${ }^{6}$ to train other physicians and therapists in the proper

62 treatment of poliomyelitis. Dr. Irwin sought the advice of Frank Krusen and asked Bennett to 63 come to GWSF as head of Physical Medicine in 1941. Bennett began classes immediately to 64 train physicians, nurses, physical therapists, occupational therapists, and social workers ${ }^{7}$ and 65 eventually many other technical personnel including orthotists and vocational counselors.

66 Insert Figures 1

\{D0427971.DOC / 1$\}$ 
Bennett $^{8}$ viewed polio "as the workshop and show case for the demonstration of the

7
physical aspects of medical care". While the Georgia Warm Springs Foundation (GWSF) was his pulpit, the physical restoration and rehabilitation of persons with polio was his sermon. In over 100 publications, he directed his teaching to all physicians, ${ }^{9-13}$ physical therapists, occupational therapist, ${ }^{14}$ nurses, vocational trainers in addition to pediatricians, ${ }^{15,16}$ orthopedic surgeons, ${ }^{17}$ and physiatrists. ${ }^{18-22}$

Few of his contemporaries demonstrated the scholarship and practice of Physical Medicine and Rehabilitation (PM\&R) with such clarity and vision. Prior to WW II, mainstream medicine gave little scientific attention or merit to chronic care and particularly the judicious use of exercise and functional retraining.

He regarded precise muscle testing as the prerequisite for muscle retraining (reeducation), which was refined by the therapists and physicians, who cared for persons with polio. Inspired by George Deaver's work on activities of daily living (ADL) with support in 1949 from a NFIP grant, he studied functional tests and training, "a natural outgrowth of muscle reeducation", in an effort to determine the values of occupational therapy in polio and other neuromuscular diseases. ${ }^{19}$

He was highly regarded by all physicians and therapists for his expertise in the treatment of polio, but had little tolerance of imprecise treatment particularly in the chronic phase. While he acknowledged with others ${ }^{23,24}$ the contributions of Sister Kenny, which elevated the importance of physical treatment in the minds of most Americans and segments of the medical profession, he was critical of her concept of pathophysiology in chronic cases, failure to use the MMT and constant revisions of the Kenny method. ${ }^{18}$ 
He set a high standard for himself and others. According to his daughter, "her father was a very strong personality, forceful and intimidating at times. "Although he had a marvelous sense of humor and was very friendly and pleasant, he had little patience with those he did not respect" (Dr. Judith Bennett Howard-Personal communication 2012). “Dr. Bennett was very strict, a perfectionist ... everything including patient care, facilities and the grounds were to be perfect, but he was affectionate toward his patients"; recalls his secretary of over 25 years, Mrs. Ethel McClure (Mrs. Ethel McClure-Personal communication).

\section{Insert Figure 2}

At Warm Springs, in the area of medical science, in addition to his emphasis on muscle testing and reeducation, Bennett demonstrated the risks of overwork to muscles ${ }^{22}$ and deformity due to muscle imbalance. He recognized the importance of activities of daily living and the need for specialized equipment and training by skilled therapists. He refined and improved the Georgia Warm Springs Feeder developed in 1936 by patient feedback and recommendations. ${ }^{25}$

\section{Insert Figure 3.}

His contribution to orthotic design and development was recognized by membership on Committee on Prosthetics Research and Development of the National Academy of ScienceNational Research Council. The refinements of orthotic devices in the treatment of polio such as the tenodesis splint and the ball bearing feeder arm remain as important adaptive equipment today in persons with spinal cord injury and other neurological disease. Following the cure for polio he redirected his interests to rheumatic diseases, which required precision in joint exercises and orthotics to prevent deformity. 
111 claimed that Bennett was a dynamic and outstanding teacher and did not receive the acclaim he

112 deserved for his many contributions to orthotic devices (Ernest Johnson 2012 Personal

113 communication).

Within several years (1945-1946) of his arrival at Warm Springs with the assistance of a 115 grant in the amount of $\$ 167,000.00$ from the National Foundation for Infantile Paralysis (NFIP), 116 Bennett established an academic department in Physical Medicine at Emory and GWSF and was 117 named Professor and Chair.

118 "The department will be operated by Emory University School of Medicine under the direction 119 of Dr. Robert L. Bennett, director of physical medicine at Georgia Warm Springs Foundation 120 and newly appointed professor of physical medicine on the medical school faculty. Dr. Bennett 121 will divide his time between Warm Springs and Atlanta.

122 The program will provide for extensive research in the field of physical medicine as applied to 123 neuromuscular diseases, particularly poliomyelitis; a schedule of training for doctors in physical 124 medicine and for technicians in physical therapy, and establishment of facilities for the treatment 125 of victims of infantile paralysis and other diseases by physical therapy. "26

127 health professionals until 1965, when he was succeeded by a fulltime physiatrist. ${ }^{27}$ In 1947

128 "residents in Physical Medicine under a program sponsored by the NFIP through Emory

129 University Medical School and GWSF (were) also given part of (their) training at Warm

130 Springs". ${ }^{7}$ He taught medical students in all four years and provided 18 hours of instruction in 
131 the sophomore year. ${ }^{28}$ He was involved in training over 100 physicians mostly in PMR and

132 some in orthopedics. ${ }^{29}$ Well known leaders in our field such as Harriet Gillette, Arthur Grant and 133 Henry Betts served as residents or fellows under Bennett's tutelage. ${ }^{29}$ From 1963-1964 Bennett 134 negotiated together with the Dean of Emory with the Vocational Rehabilitation Administration 135 (VRA) in the creation of the $6^{\text {th }}$ Research and Training Center (RT-6) and the hiring of the first 136 full time physiatrist trained by Bennett at GWSF to the faculty of Emory University Medical 137 School. ${ }^{30}$ He facilitated the creation of the Residency Program in PM\&R at Emory University 138 (EU) at the request in 1966 of Dr. Mitch Pesczyzinski, named Chair of PMR in 1965, by phasing 139 out his program at GWSF/EU, ${ }^{31}$ which had existed prior to the creation of the specialty board 140 (ABPM) in 1947. Bennett continued to serve as Professor of PM\&R and periodically as

141 Training Director of residents and medical student with federal grants up until $1980,{ }^{32} 4$ years 142 after his retirement from the GWSF. In recognition of his contributions the Robert L Bennett 143 award for excellence in teaching to residents in the Department of Rehabilitation Medicine at the 144 Emory School of Medicine is awarded. ${ }^{33}$

\section{LEADERSHIP ON THE ABPMR AND VISION OF SUBSPECIALIZATION}

It should be no surprise that as a young and energetic physician at age 36 , he served as 147 secretary-treasurer (1947-1953) on the first American Board of Physical Medicine established in $148 \quad 1947 .^{34}$

\section{Insert Figure 4.}

He not only understood the role of the physiatrist but provided leadership as an officer for

15114 years and the longest tenure at Chair of the ABPMR from 1953-1963. ${ }^{34}$ Since certification of 
152 competence in specialty practice is awarded by the specialty board, who would be in a better 153 position to define it? During these years he wrote more than 20 articles in which he illustrated 154 the role of the physiatrist especially in the care of poliomyelitis. In his Coulter lecture of $1959,{ }^{35}$ 155 he defined the role of the physiatrist of that time as having evolved to the complete physician in 156 the "handling" of all medical problems of disease of the neuromuscular and musculoskeletal 157 systems. He stated that the physiatrists' fellow physicians were beginning to understand the role 158 of allied health professions (paramedical disciplines) in the care of patients with these diseases, 159 but "tomorrow's physiatrist" will need to demonstrate his mastery of the total care 160 (rehabilitation) by utilizing the resources of data collection and assessments by paramedical staff 161 much like other doctors use laboratory data and x-rays.

"what is now (today) called the practice of physical medicine and rehabilitation... may

163 be simply stated. First, the physiatrist is reclaiming his rights and responsibilities as a physician $164 \ldots$ handling all the usual medical problems inherent in those conditions that he treats, and is not 165 limiting his medical practice to the prescription of physical agents and the supervision of 166 technical specialties.... such conditions as the primary diseases of muscle, diseases of both 167 sensory and motor pathways as they affect motor ability, and the diseases of the musculoskeletal 168 system. Second, the physiatrist is finally being accepted by his medical colleagues as a specialist 169 in those diseases that commonly result in physical disability and can be modified by the tools of 170 physical medicine and the proper utilization of the paramedical disciplines (allied health 171 professions). 
175 systems. For his patients who need more than definitive medical and surgical care, he will utilize

176 the skills of many paramedical disciplines. He will have the ability to interpret, correlate, and

177 utilize test data from these disciplines much as any physician or surgeon, regardless of specialty,

178 now utilizes data received from the X-ray department or the clinical laboratory., ${ }^{, 35}$

179

180

181

182

183

184

185

186

187

188

189

190

191

192

193

194

195

196

197 immediately, before irreversible damage occurs. other diseases. ${ }^{8}$

In his same editorial in 1969 he indicated that the lessons of polio would have benefit for

"knowledge and experience gained from polio was immediately applicable to the care of the paraplegic, the hemiplegic, the quadriplegic and even the severely brain damaged patient. It should be remembered that the first step taken toward providing the necessary care for patients with these far more complicated problems was treating patients with poliomyelitis. ${ }^{8}$

Bennett's prediction of application to future challenges such as spinal cord injury was right on target. The clinical relevance of the manual muscle test (MMT) to the accurate assessment of the severity of spinal cord injury continues to manifest itself in planned clinical trials, prediction of neurological recovery, the potential of persons with paralysis to achieve future independence in their daily lives and in the daily care of patients. It is the critical component of the ASIA International Standards for Neurological Assessment, which has become the "gold standard" of outcome measures for use in clinical trials to evaluate the benefit of nerve regeneration. ${ }^{36}$ Change in the strength of 20 muscles in the arms and legs, tells us if a drug or surgery works. Accuracy in measuring the strength of several muscles in the legs and sensation following acute SCI enables us to predict who will recover walking function. ${ }^{37}$ Loss of muscle strength in the hours following acute SCI alerts us to the potential need to change our treatment $\{$ D0427971.DOC / 1$\}$ 
198

199

200

201

202

203

204 205 as in polio.

206

207

208

209

210

211

212

213

214

215

216

217 capacities as advisor to Vocational Rehabilitation at regional and national levels. When GWSF

218

219

The same precision of muscle testing necessary to guide physicians and therapists in the treatment of poliomyelitis 70 years ago applies to SCI today. Those physicians and therapists, who defined the MMT and then refined it in the "workshop" of treatment centers for polio have provided us a legacy that survives. As Bennett taught us, the precise measure of strength guided exercise interventions as to the timing and intensity. Assessment of muscle imbalance and posture where the pull on one side would produce a contracture on the opposite applies to deformities and the need for prevention, correction with orthotics or surgery just as much in SCI

A current chair of an academic program interprets Bennett's comments in 1969 as predictive of the need for more "complex" training (fellowships) in the subspecialty areas that the ABPMR has only recognized over the past 10 years. "Bennett not only mentions the need for more specialized training in SCI and Brain trauma, but he (actually) practiced pediatric and neuromuscular medicine" (William Pease- Personal communication 2012).

Dr. Bennett's leadership at the GWSF and academic contributions was appreciated by international, numerous national and regional societies/agencies and especially by the American Congress of Physical Medicine and Rehabilitation. He not only served as president (1951-1952), but received its two highest awards; the Gold Medal and the John Stanley Coulter Lecture. A year following his retirement in 1976, he receive the Physician of the Year Award (1977) from the President's Committee for Employment of the Handicapped and served in numerous was running a low census and viewed closing its doors in 1973, Bennett together with others negotiated the sale to the State of Georgia. ${ }^{38}$

\{D0427971.DOC / 1 \} 
In his writings and lectures he recognized the link between physical restoration by therapists and physicians with the social needs (psycho-social and vocational) of individuals with severe impairment. Georgia Warm Springs had provided the workshop/environment of independent living 60 years before the disability rights movement, ${ }^{39}$ so that advances in medical science were married to the independent living movement through the bridge of rehabilitation in the 1950s. Howard Rusk ${ }^{40}$ acknowledged as the father of rehabilitation, brought rehabilitation to the world, but few programs had the unique environment of GWSF inspired by FDR (1926 1945) and the opportunity for scientific and medical leadership by Dr. Robert L Bennett (19411976) to demonstrate a model of "Rehabilitation" 7 years prior to the founding by Rusk of the Institute for Physical Medicine and Rehabilitation at New York University.

\section{Insert Figure 5}

Bennett first met Franklin Delano Roosevelt at the GWSF in 1941 shortly before FDR was called back to Washington following the attack on Pearl Harbor. FDR was a frequent visitor to the GWSF and with his remarkable memory knew each of the children by name. On the day FDR died Bennett recalls that they awaited him with the children for a barbecue and minstrel show. When the announcement was made, Bennett recalled "the children began crying, their tears mixing into the black on their faces. A great man had gone. To the nation he was a great statesman...And to us, especially he was a friend. ${ }^{, 41}$

His long time colleague for over 30 years, Dr. Hal (Pat) Raper (see photo Fig. 2 ), praised him as "internationally famous (and) a dedicated person. ${ }^{, 42}$ His son, Dr. Hal Raper, Jr., recalls they played golf every week (personal communication Hal Raper, Jr.). Hal Raper Jr. and both Bennett daughters, Judith and Susan were born in Warm Springs. The families were close 
242 friends (Dr. Judith Bennett Howard and Dr. Hal Raper, Jr.- personal communications) and both

243 the Raper and Bennett parents are interred at the GWSF cemetery, a small and private lot

244 immediately adjacent to the golf course.

245 Bennett, a native of Pennsylvania, graduated from the University of Pittsburg, School of

246 Medicine in 1936 before going to the Mayo Clinic for residency training. Inspired by Krusen and

247 a new dimension of being a physician he chose GWSF as the environment for the realization of

248 his vision. His fulfillment was tenure of thirty five years (1941-1976) dedicated to his profession

249 and the people he loved. It is fitting that upon his passing on Friday, July 28, 1983, he was laid to

250 rest in the Georgia Warm Springs Foundation cemetery with his father, family and friends

251 "Lest we forget", the legacy of Franklin Delano Roosevelt, ${ }^{43}$ the Georgia Warm Springs

252 Foundation and Dr. Robert L Bennett, pioneer in Physical Medicine and Rehabilitation, let us

253 remember the hundreds of dedicated professionals and thousands of persons with polio, who

254 working together sought full citizenship and participation in our society. Let us be mindful that

255 the lessons learned from polio assessment and treatment, continue to benefit persons with severe

256 impairments due to spinal cord injury and other neurological diseases.

258 Acknowledgements

259 The author (s) wish to acknowledge the assistance of Michael Shadix, archivist, Professional

260 Library Roosevelt Institute, Warm Springs, Georgia, Dr. David Burke, Chair of the Department

261 of Rehabilitation, Emory University School of Medicine and Dr. Donald Leslie, Director of the

262 Regional Model SCI Center at Shepherd Hospital, Atlanta, Georgia.

$\{$ D0427971.DOC / 1$\}$ 
264 1. Verville R. War, Politics, and Philanthropy: The History of Rehabilitation Medicine. Lanham, 265 Maryland: University Press of America; 2009.

266 2. Johnson EW. PM\&R: Where we have been, where we are heading. PMR. 2009;1:3-4.

267 3. Martin GM. Building on the framework: The academy in the 1950s. Arch Phys Med Rehabil 268 1988;69 Spec No:15-19.

269

270

271

272

273

274

275

276

277

278

279

280

281

282

283

284

4. Delisa JA, Martin GM, Currie DM. Rehabilitation medicine: past, present and future. In: DeLisa JA GB, ed. Rehabilitation Medicine: Principles and Practice. Philadelphia: Lippincott-Raven; 1998:3-32.

5. Opitz JL, Folz TJ, Gelfman R, Peters DJ. The history of physical medicine and rehabilitation as recorded in the diary of Dr. Frank Krusen: Part 1. Gathering momentum (the years before 1942). Arch Phys Med Rehabil. 1997 Apr;78(4):442-5.

6. Walker T. Roosevelt and the Warm Springs Story. New York: AA. Wyn; 1953. 262-263.

7. Georgia Warm Springs Foundation. Annual Report September 30, 1948: Professional Training. Archives Roosevelt Warm Springs Institute for Rehabilitation, Warm Springs, Georgia. Available at http://wwwcf.nlm.nih.gov/hmddirectory/directory/collections.cfm?id=39. Accessed 5-152012

8. Bennett RL. The contribution to physical medicine of our experience with poliomyelitis. Arch Phys Med Rehabil. 1969;50:522-524.

9. Bennett RL. Physical treatment of poliomyelitis; responsibilities of the physician in general practice. J Am Med Assoc. 1949;139:1053.

\{D0427971.DOC / 1$\}$ 
285 10. Bennett RL. Care of children convalescing from poliomyelitis; discussion of several points of controversy. J Am Med Assoc. 1950;144:377-379.

287 11. Bennett RL, Stephens HR. Care of severely paralyzed upper extremities. J Am Med Assoc. 1952;149:105-109.

289 12. Bennett RL. Role of physician in prevention of musculoskeletal deformity after 290 poliomyelitis. J Am Med Assoc. 1953;153:79-81.

291 13. Bennett RL. Evaluation of end-results of acute anterior poliomyelitis. J Am Med Assoc. $292 \quad 1956 ; 162: 851-854$.

293 14. Bennett RL, Driver MF. The aims and methods of occupational therapy in the treatment of 294 the after-effects of poliomyelitis. Am J Occup Ther. 1957;11:145-153.

295 15. Bennett RL. The role of physical medicine in poliomyelitis. J Pediatr. 1946;28:316-323.

296 16. Bennett RL. Functional training of the polio child. Nerv Child. 1956;11:47-52.

297 17. Bennett RL. Poliomyelitis; convalescent treatment and related subjects. Arch Surg. 298 1947;54:476-482.

299 18. Bennett RL. The influence of the Kenny Concept of acute poliomyelitis on the physical 300 treatment throughout all stages of the disease. Arch Phys Therapy. 1943;24:453-460.

301 19. Bennett RL. Functional testing and training in physical medicine. Arch Phys Med Rehabil. 302 1949;30:263-271.

303 20. Bennett RL. The training of the physiatrist. Arch Phys Med Rehabil. 1952;33:585-588.

304 21. Bennett RL. Classification and treatment of early lateral deviations of the spine following 305 acute anterior poliomyelitis. Arch Phys Med Rehabil. 1955;36:9-17.

306 22. Bennett RL, Knowleton GC. Overwork. Arch Phys Med Rehabil. 1956;9:473-476. 
307

308

309

310

23. Knapp M. The contribution of Sister Elizabeth Kenny to the treatment of poliomyelitis. Arch Phys Med Rehabil. 1955;36:510-517.

24. Cohn V. Sister Kenny. The woman who challenged the doctors. Minneapolis: University of Minnesota Press; 1976.

25. Bennett R. The Evolution of the Georgia Warm Springs Foundation Feeder. Artificial Limbs. 1966;2:5-9.

26. Medical News. Georgia. JAMA 1946;130(1):42-44.

27. Peszczynski, M. Letter to Dr. Robert L. Bennett June 23, 1965. Dr. Robert Bennett's Files, Vocational Rehabilitation Division, RG 75, Box 21, Georgia Archives. Available at http://find.sos.state.ga.us/archon/index.php?p=collections/controlcard\&id=2267\&q=rober t+l+bennett. Accessed 5-18-2012.

28. Emory University School of Medicine Catalogue. Physical Medicine: R.L. Bennett Professor and Chair 1960-1961. Archives Roosevelt Warm Springs Institute for Rehabilitation, Warm Springs GA. Available at Available at http://wwwcf.nlm.nih.gov/hmddirectory/directory/collections.cfm?id=39 Accessed 515-1961.

29. Bennett RL. List of Physical Medicine Fellows and Residents 1947-1965. Archives Roosevelt Warm Springs Institute for Rehabilitation, Warm Springs GA. Available at http://wwwcf.nlm.nih.gov/hmddirectory/directory/collections.cfm?id=39 Accessed 5-152012.

30. Bennett RL. Letter to Basil O'Connor September 20, 1963. Dr. Robert Bennett's Files, Vocational Rehabilitation Division, RG 75, Box17, Georgia Archives. Available at 
http://find.sos.state.ga.us/archon/index.php?p=collections/controlcard\&id=2267\&q=rober t+l+bennett. Accessed 5-18-2012.

31. Peszczynski, M. Progress Report 1965 to 1966; RT-6 Emory University to Vocational Rehabilitation Administration, HEW. Dr. Robert Bennett's Files, Vocational Rehabilitation Division, RG 75, Box 21, Georgia Archives. Available at http://find.sos.state.ga.us/archon/index.php?p=collections/controlcard\&id=2267\&q=rober t+l+bennett Accessed 5-18-2012.

32. Bennett RL. Grant Award for Teaching Medical Students and Residents 1977-1980, Vocational Rehabilitation Administration. MARBL Emory University Box 15, Folder 5. Available at http://marbl.library.emory.edu/. Accessed 3-21-2012.

\section{3._Robert L. Bennett Award for Teaching Excellence. Rehabilitation Department Awards.}

Emory University School of Medicine Teaching Awards. Available at http://www.emory.edu/TEACHING/TeachingEmory/Awards/MedicineMenu.htm. Accessed 3-21-2012

34. American Board of Physical Medicine and Rehabilitation. Board History: In appreciation. Booklet of Information Certification 2011-2012. American Board of Physical Medicine and Rehabilitation, 47. 2012. Available at https://www.abpmr.org/boi/Cert_BOI.pdf. Accessed 4-4-2012.

35. Bennett RL. The ninth John Stanley Coulter Memorial Lecture: tomorrow's physiatrist. Arch Phys Med Rehabil. 1960;41:89-94.

36. Ditunno JF. Outcome measures: evolution in clinical trials of neurological/functional recovery in spinal cord injury. Spinal Cord. 2010;48:674-684. 
351 37. van Middendorp JJ, Hosman AJ, Donders AR et al. A clinical prediction rule for ambulation

352

353

354

355

356

357

358

359

360

361

362

363 outcomes after traumatic spinal cord injury: a longitudinal cohort study. Lancet. 2011;377:1004-1010.

38. Georgia Warm Springs Foundation. Archives Roosevelt Warm Springs Institute for Rehabilitation, Warm Springs, Georgia. Available at http://wwwcf.nlm.nih.gov/hmddirectory/directory/collections.cfm?id=39..Accessed 5-152012

39. Halstead L.S. Post-Polio Syndrome. First edition. Philadelphia: Hanley \& Belfus; 1995.

40. Rusk HA. A World To Care For: The Autobiography of Howard A. Rusk. Readers Digest/Random Press, New York, 1972.

41. Azer M. Dr. R. L Bennett, Who Knew FDR Personally, Charlotte Visitor. Charlotte News. April 14, 1945;1B. Archives Roosevelt Warm Springs Institute for Rehabilitation, Warm Springs GA. Available at http://wwwcf.nlm.nih.gov/hmddirectory/directory/collections.cfm?id=39. Accessed 5-172012.

42. Betty L. Dr. Robert L. Bennett, Obituary. Enquirer Columbus GA. July 28, 1983. Archives Roosevelt Warm Springs Institute for Rehabilitation, Warm Springs GA. Available at Available at http://wwwcf.nlm.nih.gov/hmddirectory/directory/collections.cfm?id=39. Accessed 5-17-2011

43. Verville RE and Ditunno, Jr. JF. FDR, polio and the Warm Springs experiment: its impact on PM\&R. PM R Vol. 5, No. 1 Jan 2013 (pending acceptance). 
$374 \quad$ Figure Legends

375 Figures 1: Bennett lecturing and demonstrating evaluation of patients to physicians, nurses and 376 therapists. Courtesy of Georgia Warm Springs Foundation.

378 Figure 2: Drs. Hal Stuart Raper, Director of Internal Medicine, Robert L. Bennett, Director of 379 Physical Medicine, Charles Edwin Irwin, Medical Director with Basil O'Connor, President of 380 GWSF. 1952. Courtesy of Georgia Archives, Vanishing Georgia Collection, mer027.

382 Figure 3: Bennett Teaching Spinal Orthotics to Physicians. Courtesy of Georgia Warm Springs 383 Foundation.

Figure 4: The original ABPMR (1947) with Frank Krusen first row center and Robert Bennett 386 right. 

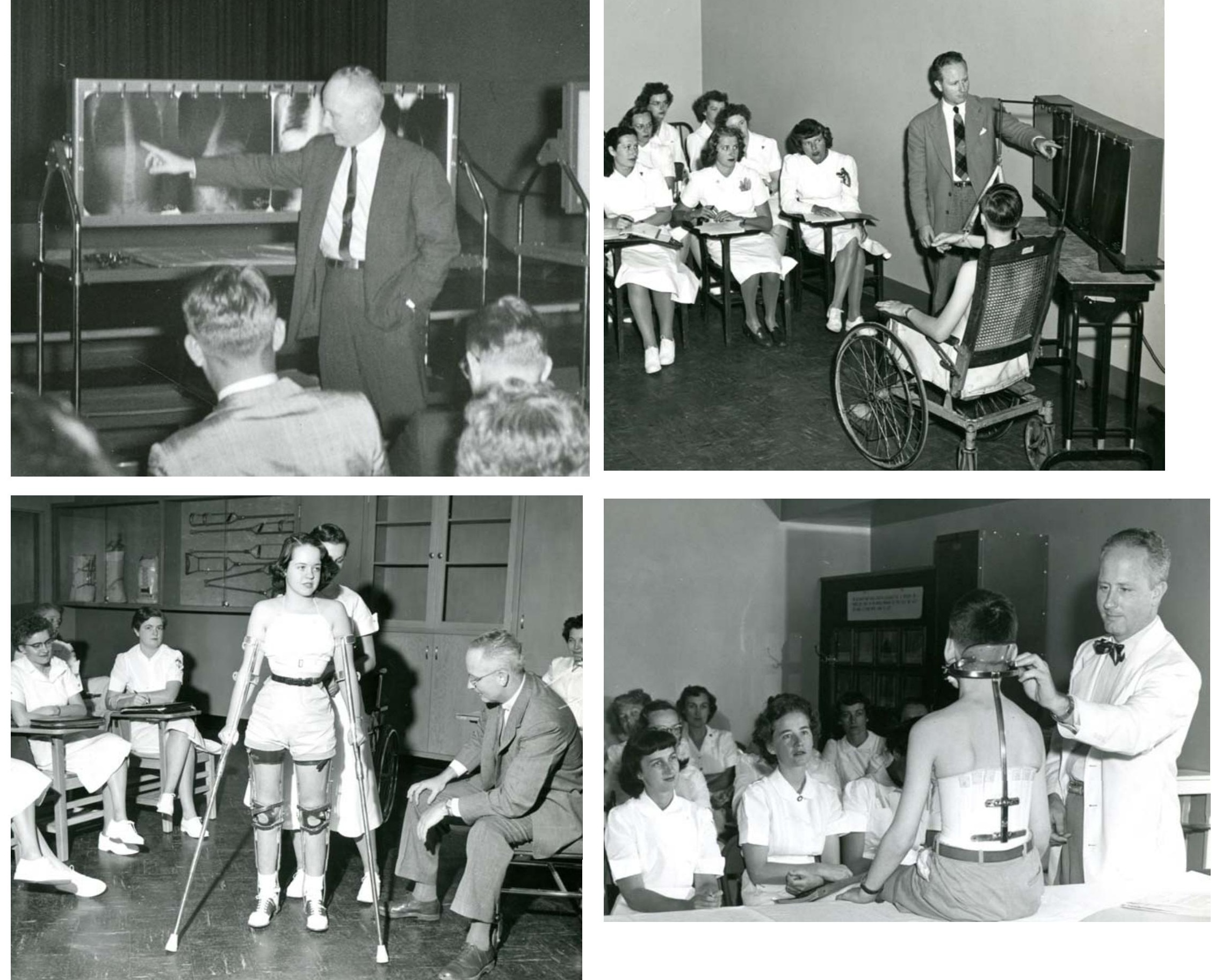
Click here to download high resolution image

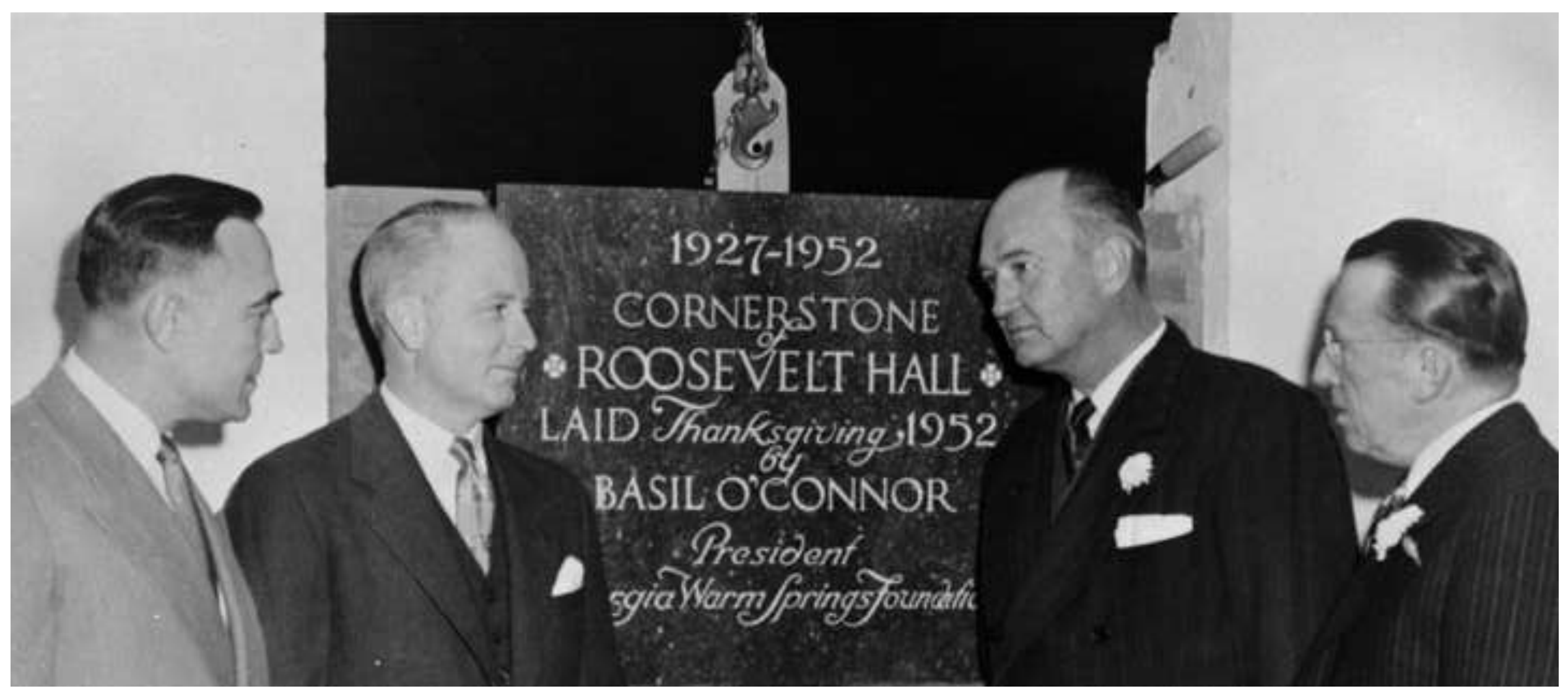


EXIT

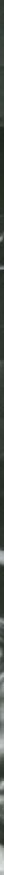

\section{Figure 3}

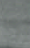

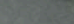


Click here to download high resolution image

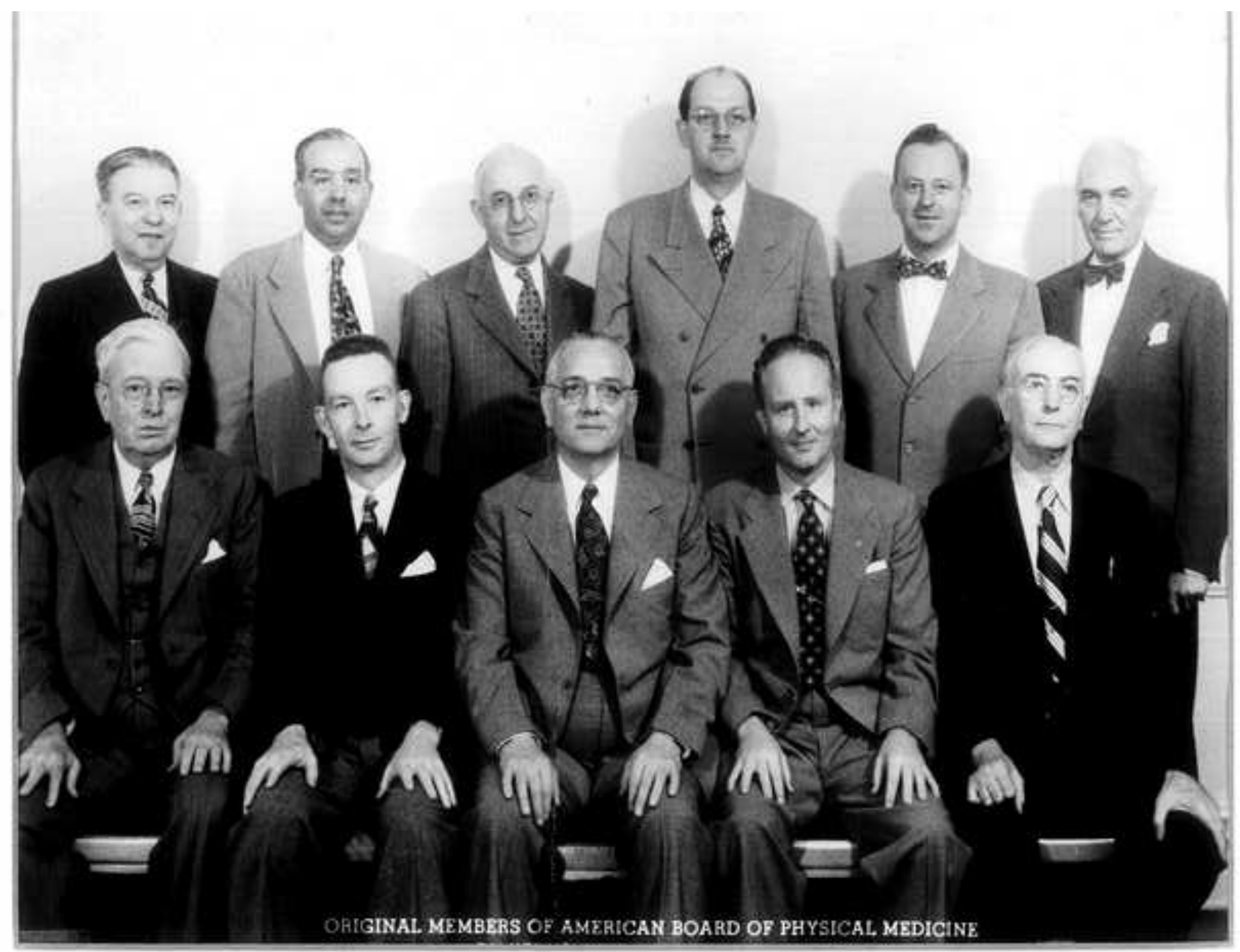

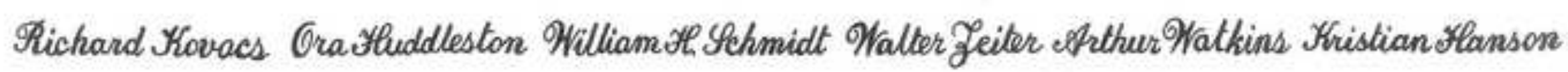
Lotn Coulter Benjamin Strickland Frank Frusen Robert BBennett FrankEWwerhardt 
November 14, 2012

M. Elizabeth Sandel, M.D.

Journal PM\&R

Editorial Office

Dear Dr. Sandel,

Please consider the manuscript entitled "Dr. Robert L. Bennett: Pioneer and Definer of Modern Physiatry" for publication in the journal of PM\&R. It is an invited article on the accomplishments of Robert L.

Bennett.

\section{Conflict of Interest Statement}

There is no Conflict of Interest for the authors, John F. Ditunno and Richard E. Verville. If you have any further questions, please feel free to contact me at 215-955-6579.

Sincerely,

John F. Ditunno, Jr., M.D.

Thomas Jefferson University

Professor, Dept of Rehabilitation Medicine 
Disclosure Form
Click here to dow

Click here to download Disclosure Form: ICMJEdisclosure_Ditunno.pdf Click here to download Disclosure Form: ICMJEdisclosure_Ditunno.pdf 
Disclosure Form
Click here to download Disclosure Form: ICMJEdisclosure_Verville.pdf

Disclosure Form
Click here to download Disclosure Form: ICMJEdisclosure_Verville.pdf

Disclosure Form
Click here to download Disclosure Form: ICMJEdisclosure_Verville.pdf

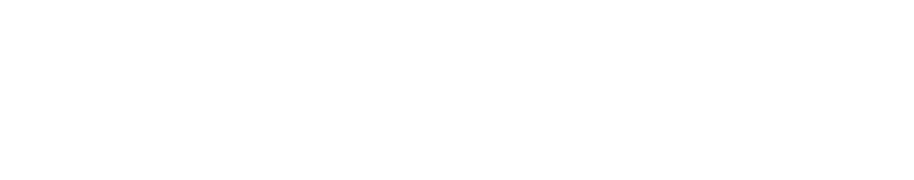

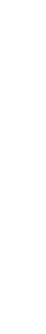

(1)

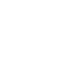

(1)

(1)

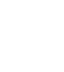

(1)

(1)

(1)

(1)

(1)

(1)

(1)

(1)

(1)

(1)

(1)

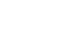

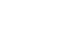

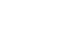

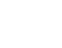

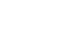

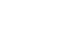

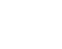

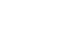

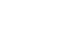

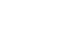

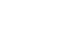

